E3S Web of Conferences 1, 32011 (2013)

DOI: $10.1051 / \mathrm{e} 3 \operatorname{sconf} / 20130132011$

(C) Owned by the authors, published by EDP Sciences, 2013

\title{
Metals complexation with humic acids in surface water of different natural-climatic zones
}

\author{
M. I. Dinu $^{1}$ \\ ${ }^{1}$ Vernadsky Institute of Geochemistry and Analytical Chemistry of Russian Academy of Sciences, \\ Russia,marinadinu999@gmail.com
}

\begin{abstract}
Humic acids extracted from different soils. The stability constants of metal humates and acid dissociation constant humic acids were calculated. Forms of metals in natural waters was determined with use account their chemical composition and content and properties of organic matter. We assessed metals speciation in water objects with account for competitive reactions resulting in formation of hydroxide, hydrocarbonate, sulfate, and chloride metal complexes and obtained a competitive series of metal activity in natural waters of the zones considered.
\end{abstract}

Key words: Heavy metals, humic acid, complexing, stability constants

\section{Introduction}

Ions of metals (IM) in aquatic systems are involved in existing migration cycles. They migrate, were accumulating in all components of the aquatic environment: in the water itself, suspended matter, bottom sediments (BS), and living organisms [2-5, 23-27]. This disturbs the interactions in aquatic ecosystems, affects their structure, and causes the appearance of technogenic geochemical anomalies. A specific feature of IM is the fact that they withstand biodegradation and can accumulate in large amounts in water, aquatic organisms, and $\mathrm{BS}[2,3,12-14,17,28$, 29]. It is common knowledge that IM ions are most toxic; therefore, data on not only on their total content, but also on the forms of occurrence are of great importance.

The organic matter $(\mathrm{OM})$ of natural waters can bind with the IM entering the system, thus reducing their toxic properties $[6,8-11,15,16,27-30]$. OM in water consist predominantly (up to $80 \%$ ) of humic acids (HA), represented by highmolecular, dyed, polyfunctional compounds $[15,16,24]$. The natural-climatic zones feature various ratios of fulvic (FA) and humic acids. The concentrations of these acids in surface waters attain $1-100 \mathrm{mg} / 1$ [2, 3]. An important specific feature of metals as contamination elements is the fact that when they occur in the environment, their potential toxicity and bioavailability depend significantly on their speciation. In recent years, lakes have been continuously enriched in hazardous elements such as $\mathrm{Pb}, \mathrm{Cd}, \mathrm{Al}$, and $\mathrm{Cr}$ on a global (regional) basis. Metals occur in natural waters as free ions, simple complexes with inorganic and organic ligands, and mineral and organic particles of molecules and ions sorbed on the surface. The occurrence of soluble metal forms in natural waters depends on the presence of organic and inorganic anions. The most important organic ligands are humic matter (HM) washed out from soils; inorganic complexes formed include hydroxide groups, hydrocarbonates, sulfates, and chlorides. However, direct determinations are rather difficult. Our current task is to develop methods that would make it possible to forecast element speciation predefining toxic properties of water by the chemical composition of the water.

\section{Materials and Methods}

The objective of this work was to investigate metals complexing with humic acids and to determine forms of metals with use experimentally obtained constants of metals complexes with humic acids and acid dissociation constant humic acids. Humic acids extracted from typical soils of different natural climatic zones because soils are the main HA sources in water objects.

Thus, the HA content and their properties in natural waters depend largely on the properties of soils located in the watershed, and, correspondingly, they have similar zonal specifics. We used the typical soils of the northern taiga zone (Polyarnye Zori district of the Kola Peninsula), mixed forest zones (Shatura, Kashirskii, and Odintsovo districts), and steppe zones (Voronezh Region). Having 
summarized different methods of HA investigation, we developed an original technique combining measurements of HA qualitative features and quantitative analysis of HA interaction with metal ions (Figure 1).

\section{Results and Discussion}

HAs of selected soil types are different in functions [4, 5], and these differences effect substantially the complexing process. When analyzing the results obtained in the course of spectrometric investigation of HMs in selected soil types, we determined the following main HA characteristics: (1) predominance of oxygen bearing groups in HM of the northern taiga soils; (2) similar amounts of oxygen bearing fragments, hydrocarbon constituents, and nitrogen bearing components in the mixed forest zones; (3) occurrence of aromatic and aliphatic hydrocarbons in HM of steppe soils.
The HM functional characteristics influence substantially the stability constants of complexes with metal ions and complex stoichiometry (Tabl. 1). Complexes of alkaliearth metals, chrome, and manganese are formed in a 1:1 ratio with HA of all selected natural zones and with low stability constants of complexes, which is related to the physicochemical properties of metal ions. Ions of trivalent iron and bivalent lead are able to form complexes with HA of the steppe zones in a $1: 2$ ratio, which is explained by the elevated contents of branched aromatic fragments in the HM structure in black soil and by the ionic radius of metals. The obtained data are in good compliance with the data of [6]. The stability constants of complexes are different for most metal ions with HM of natural zones (Table 1), which also indicates the specificity of the complexing processes. Differences in values of constants are caused by the physicochemical properties of metals and qualitative features of soil HA.

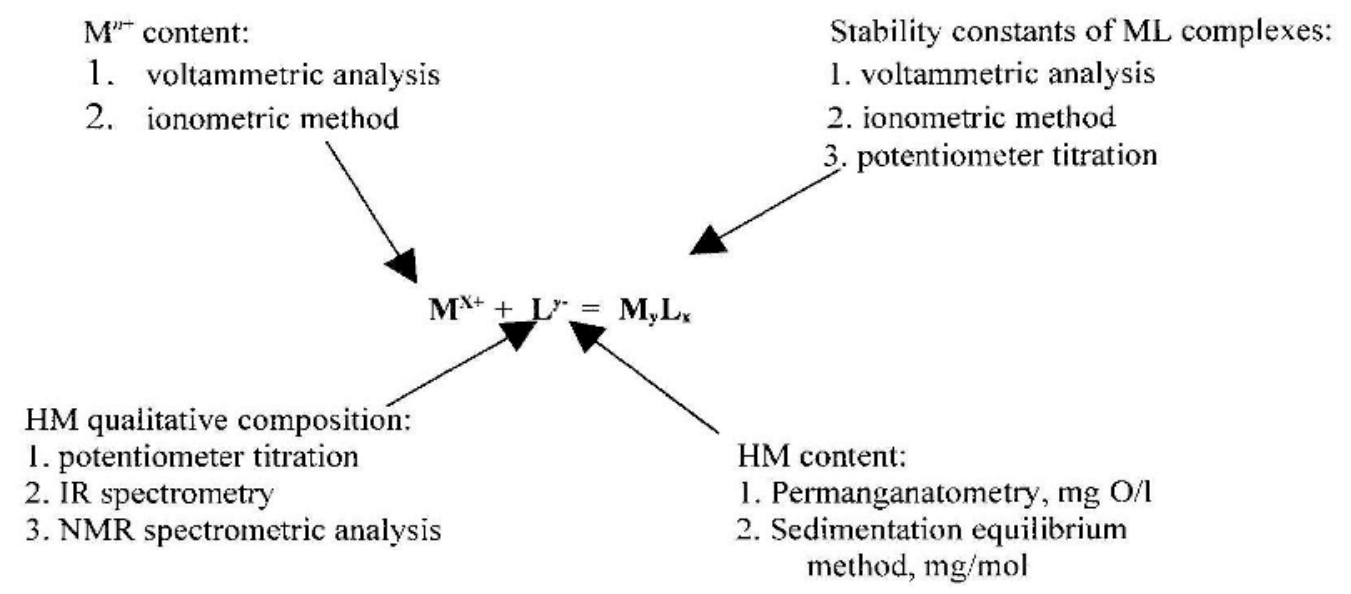

Fig. 1 General chart of metal and soil HM complexing. $\left(\mathrm{M}^{x+}\right.$ is metal cations, $\mathrm{L}^{y-}$ is the humic matter anion, and $\mathrm{M} y-\mathrm{L} n$ is the complex of metal with humic matter)

The stability constants of iron complexes with HA in the northern taiga zone are much higher than those in the steppe zone; this difference is caused by the predominance of oxygen bearing fragments (Pearson's hard centers) in HA of this zone [7]. Ions of trivalent iron like Pearson's hard acid are characterized by a high affinity to oxygen bearing groupsand, thus, to HM of the taiga zone. As for copper compounds, the stability constant of complexes is higher inreactions with HA of the steppe zones. This fact is related to the prevalence of softer Pearson's centers. Ions of bivalent copper like Pearson's softer acid are able to form bonds through softer centers which are predominant in HM of the steppe soils. Stability constants of lead complexes with $\mathrm{HM}$ are also different by a few orders of magnitude, which is related to the physicochemical properties of metal ions, such as Pearson's intermediate acid, and HM specific features. Lead is able to bind to oxygenbearing groups (Pearson's hard centers) and to sulfur and carbon bearing groups (Pearson's soft centers).

Stability constants of metal and HM complexes in typical soils of natural climatic zones obtained in the course of the experiment were used for determination of metal speciation in natural waters of different zones.

Along with the data obtained in the course of the experiment, the process of competitive reactions of metal hydroxide complex formation and also formation of hydrocarbonate, sulfate, and chloride complexes of metals were taken into account [8]. Calculations based on data on the water chemical composition in small lakes obtained in the course of comprehensive investigations in zones such as the taiga, mixed forests, and steppes. The characteristics of the methods and water chemical composition in different natural climatic zones are described in [9]. After verification of the calculated data with experimental data on the forms of metals in waters of the Kola Peninsula [9-10], we have obtained a high 
Table 1. Stability constants $(\lg K)$ of metal and HM complexes in soils of natural zones

\begin{tabular}{|c|c|c|c|c|}
\hline \multirow[b]{3}{*}{ Metals } & \multirow[b]{3}{*}{$\lg \mathrm{K}_{1,2}$} & \multicolumn{3}{|c|}{$\operatorname{lgK}$} \\
\hline & & \multicolumn{3}{|c|}{ natural-climatic zones } \\
\hline & & Steppe & Mixed forest & Northern taiga \\
\hline \multirow[b]{2}{*}{$\mathrm{Cu}(\mathrm{II})$} & $\lg \mathrm{K}_{1}$ & $8,0 \pm 0,3$ & $6,5 \pm 0,3$ & $5,7 \pm 0,3$ \\
\hline & $\lg \mathrm{K}_{2}$ & - & $12,9 \pm 0,3$ & $10,3 \pm 0,5$ \\
\hline \multirow[b]{2}{*}{$\mathrm{Pb}(\mathrm{II})$} & $\lg \mathrm{K}_{1}$ & $4,5 \pm 0,4$ & $5,2 \pm 0,5$ & $6,7 \pm 0,3$ \\
\hline & $\lg K_{2}$ & $7,2 \pm 0,5$ & - & - \\
\hline $\mathrm{Zn}(\mathrm{II})$ & $\lg \mathrm{K}_{1}$ & $4,7 \pm 0,5$ & $5,4 \pm 0,5$ & $3,7 \pm 0,5$ \\
\hline $\mathrm{Cd}(\mathrm{II})$ & $\lg \mathrm{K}_{1}$ & $3,7 \pm 0,4$ & $3,7 \pm 0,3$ & $4,1 \pm 0,3$ \\
\hline \multirow[b]{2}{*}{$\mathrm{Fe}(\mathrm{III})$} & $\lg \mathrm{K}_{1}$ & $8,2 \pm 0,4$ & $7,7 \pm 0,3$ & $10,2 \pm 0,4$ \\
\hline & $\lg \mathrm{K}_{2}$ & $16,0 \pm 0,5$ & - & - \\
\hline $\mathrm{Ni}(\mathrm{II})$ & $\lg K_{1}$ & $5,0 \pm 0,5$ & $5,7 \pm 0,3$ & $4,5 \pm 0,3$ \\
\hline $\mathrm{Co}(\mathrm{II})$ & $\lg K_{1}$ & $3,9 \pm 0,5$ & $4,8 \pm 0,2$ & $5,8 \pm 0,3$ \\
\hline $\mathrm{Cr}(\mathrm{III})$ & $\lg K_{1}$ & $2,5 \pm 0,3$ & $3,2 \pm 0,5$ & $3,5 \pm 0,4$ \\
\hline $\mathrm{Mn}(\mathrm{II})^{*}$ & $\lg \mathrm{K}_{1}$ & $2,4 \pm 0,3$ & $3,2 \pm 0,3$ & $2,8 \pm 0,2$ \\
\hline
\end{tabular}

Note: $n$ is the ratio of metal-ligands in the complex, where $n$ varies depending on the number of ligands ( 1 or 2$)$ related to metals. The average values are indicated above the bar, while the interval is indicated below the bar.
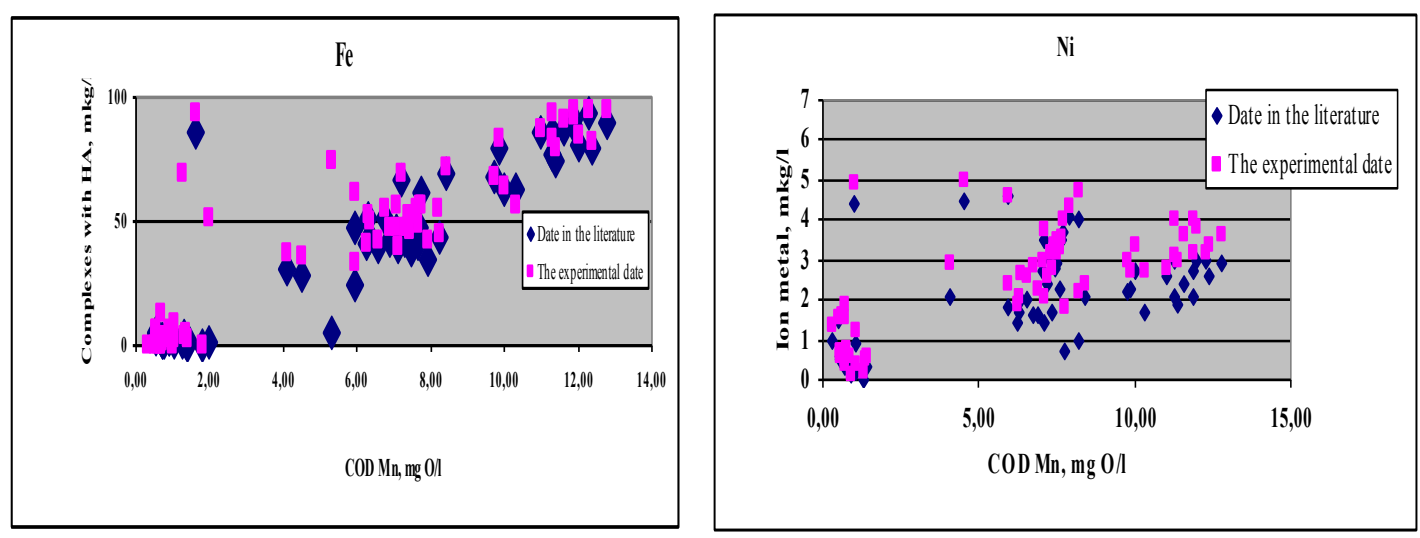

Fig. 2 Verification of the calculated data

degree of convergence: more then $95 \%$ (Fig. 2).

\section{Conclusion}

Quantity of metals bound into complexes and their competitive series depend not only on the properties of metal ions, but on the general chemical quality of waters. Metal speciation in natural waters is conditioned by the contents of HM organic ligands washed away from soils, their acidic-basic properties, the compositions and concentrations of all metals, and also inorganic anions such as hydroxide groups, hydrocarbonates, sulfates, and chlorides.

Humic acids contribute the most substantially to metal inactivation. When defining water quality standards and estimating ecological consequences of water contamination with metals, it is necessary to take into account their occurrence forms depending on the chemical composition of natural waters. The obtained results concerning metal migration forms in natural waters make it possible to correct quality standards and to estimate the real ecotoxic situation in water reservoirs contaminated by a wide range of metals.

\section{References}

1. T.I. Moiseenko, L.P. Kudryavtseva, and N.A. Gashkina, Scattered Element in Surface Land Waters: Technophility, Bioaccumulation, and Ecotoxicology (Nauka, Moscow, 2006) [in Russian].

2. G. M. Varshal, Ext. Abstr. Doct. Dis. Chem. (Inst. Geokh. Analit. Khim. RAN, Moscow, 1994).

3. I.A. Lapin and V. N. Krasyukov, Okeanologiya 26, 621-627 (1986). 
4. D.S. Orlov, Humic Acids (MGU, Moscow, 1986) [in Russian].

5. D.V. Kovalevsky, Ext. Abstr. Cand. Dis. Chem. (MGU, Moscow, 1998).

6. I.A. Linnik and B. I. Nabivanets, Metal Migration Forms in Surface Fresh Waters (Gidrometizdat, Leningrad, 1985) [in Russian].

7. Hartley, F., Burgess, C., and Alcoc, R., Solution Equilibria (Ellis Horwood, Chichester (UK), 1980).
8. Yu. Yu. Lur'e, Reference Book of Physicochemical Values (Nauka, Moscow, 2000) [in Russian].

9. T.I. Moiseenko and N.A. Gashkina, Formation of Water Chemical Composition under Anthropogenic.

10. T.I. Moiseenko, I.V. Rodyushkin, V.A. Dauvalter, Formation of water quality and sediment conditions in the anthropogenic load on the ponds of the Arctic basin (on the example of the Kola Peninsula). (Izd RAS, Apatity, 1996) [in Russian]. 